\title{
Sphingosine-1-phosphate Receptor Modulators in Multiple Sclerosis
}

\author{
Patrick Vermersch
}

University of Lille, CHU Lille, INSERM U995 (LIRIC), FHU Imminent, Lille, France

$\mathrm{T}$ he introduction of oral disease modifying therapies has transformed the treatment landscape for patients with multiple sclerosis (MS). Fingolimod (Gilenya ${ }^{\oplus}$, Novartis, Basel, Switzerland), the first oral therapy to be approved, has demonstrated clinical efficacy as a result of modulation of subtype 1 sphingosine-1-phosphate $\left(\mathrm{S}_{\mathrm{P}} \mathrm{P}_{1}\right)$ receptors. This leads to retention of lymphocytes in the lymph nodes, preventing their entry into the central nervous system. However, fingolimod can cause adverse effects as a result of its interaction with other S1P receptor subtypes, which are expressed in numerous tissues, including cardiac myocytes. More selective S1P receptor agents are currently in phase II and III clinical development. Siponimod, ozanimod, ponesimod and amiselimod have demonstrated efficacy with improved safety profiles compared with fingolimod. While more long-term data are needed, these selective S1P receptor modulators appear to be promising options for the treatment of MS and other disorders associated with autoimmunity and inflammation.

\section{Keywords}

Multiple sclerosis, oral disease modifying therapies, sphingosine-1-phosphate receptors

Disclosure: Patrick Vermersch has received honoraria and consulting fees from Biogen, Sanofi-Genzyme, Novartis, Teva, Merck, Roche, Servier, Celgene, Medday and Almirall. He has also received research support from Biogen, Novartis, Sanofi-Genzyme, Roche and Merck.

Review Process: Double-blind peer review

Acknowledgements: Medical writing support was provided by Katrina Mountfort of Touch Medical Media, and was supported by Touch Medical Media. Compliance with Ethics: This article involves a review of the literature and did not involve any studies with human or animal subjects performed by the author.

Authorship: The named author meets the criteria of the International Committee of Medical Journal Editors for authorship of this manuscript, takes responsibility for the integrity of the work as a whole and has given final approval for the version to be published.

Open Access: This article is published under the Creative Commons Attribution Noncommercial License, which permits any non-commercial use, distribution, adaptation and reproduction provided the original author and source are given appropriate credit. (c) The Author 2018

Received: 31 January 2018

Accepted: 21 March 2018

Citation: European Neurological

Review. 2018;13(1):25-30

Correspondence: Patrick Vermersch, University of Lille, CHU Lille, INSERM U995 (LIRIC), FHU Imminent, F-59000 Lille, France. E: patrick.vermersch@univ-lille2.fr

Support: No funding was received in the publication of this article.
In the past decade, a number of novel therapies targeting specific molecules involved in the inflammatory or immune system activation cascades have become available, improving the management of multiple sclerosis (MS). ${ }^{1}$ However, most new therapies are biological drugs, which need to be injected and are therefore associated with reduced convenience, compliance and injection- or infusion-related adverse effects (AEs). ${ }^{2,3}$ Most current disease modifying therapies (DMTs) for MS primarily target the immunological inflammatory component of the disease without acting directly on the central nervous system $(\mathrm{CNS})^{4}$ and have been shown to be only partially effective. In addition, chronic immunosuppression is associated with mainly opportunistic infections. ${ }^{5}$

Another drawback of current DMTs is that, to date, most have shown limited efficacy against secondary progressive MS (SPMS), ${ }^{6}$ although ocrelizumab has been approved for progressive MS after showing activity in patients with primary progressive MS.? A new class of oral targeted therapies for MS has the potential to overcome these limitations. This review aims to discuss the clinical development of sphingosine-1-phosphate (S1P) receptor modulators for the treatment of patients with relapsing forms of MS (RMS) or SPMS.

\section{Mechanism of action of sphingosine-1-phosphate receptor modulators}

Sphingosine-1-phosphate is an active phospholipid that is produced by the phosphorylation of sphingolipids, present in the cell membrane, by sphingosine kinase-1 or -2 (SphK1/2; Figure 1). ${ }^{8}$ It regulates numerous biological processes including immunity, inflammation, angiogenesis, heart rate, smooth muscle tone, cell differentiation, cell migration and survival, calcium homeostasis and endothelium integrity, and is found in high concentrations in erythrocytes, brain, spleen and eyes. ${ }^{8}$ Its effects are mediated by S1P receptors, which have seven transmembrane segments and are coupled to G-proteins. There are five known subtypes: S1 $_{1-3}$ which are broadly distributed in tissues; $\mathrm{S} \mathrm{P}_{4}$, which is expressed mostly in lymphoid tissue and the lungs; and $\mathrm{S} \mathrm{P}_{5}$, which is found in the spleen, skin and oligodendrocytes. ${ }^{8,9}$ Therefore, S1P receptors are found in multiple organ systems including the immune, cardiovascular, and respiratory systems, as well as in the CNS. ${ }^{9}$ In the CNS, expression of S1P receptors has been reported on oligodendrocytes, astrocytes, neurons and microglia in experimental conditions. ${ }^{9}$ Both B- and T-lymphocytes express $\mathrm{S}_{1} \mathrm{P}_{1}$ and,

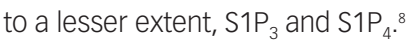

Sphingosine-1-phosphate signalling plays an important role in lymphocyte trafficking, particularly egress from lymph nodes and migration into the blood and target tissues (Figure 1). ${ }^{10,11}$ In patients with MS, S1P receptors reduce the release of lymphocytes from secondary lymphoid tissues, thymus and bone marrow, resulting in Iymphopaenia. The binding of S1P receptor modulators to $\mathrm{S}_{1} \mathrm{P}_{1}$ on central memory T-cells (TCM) causes these cells to internalise their own S1P 1 , resulting in TCM that no longer respond to S1P signals. Any new S1P receptors produced inside the cell remain in an inactive state until S1P receptor modulation is removed. ${ }^{11}$ 
Figure 1: Mechanism of action of sphingosine-1-phosphate receptor modulators

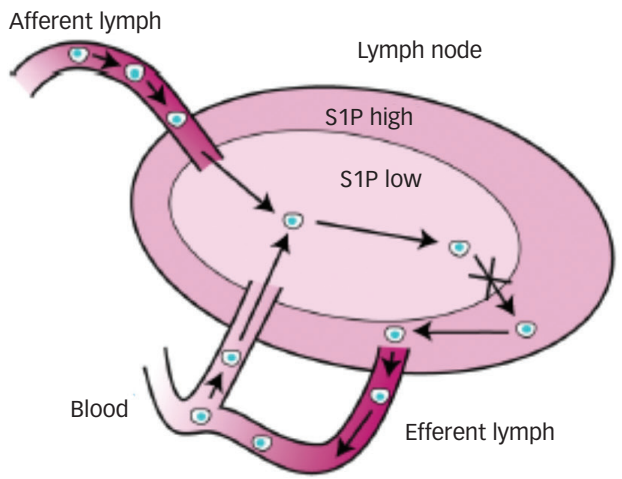

X Fingolimod inhibits S1P-S1P -directed lymphocyte egress

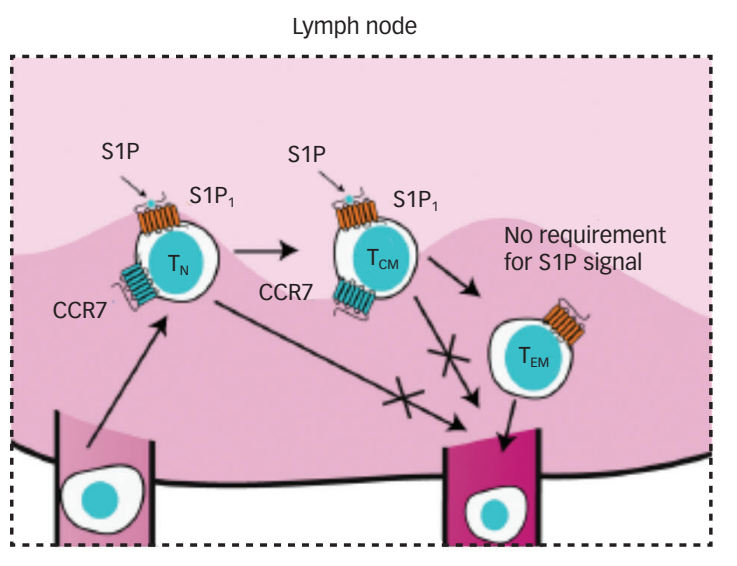

Blood

C

Agent

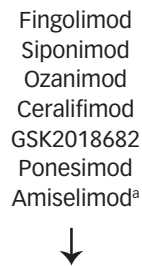

Receptor

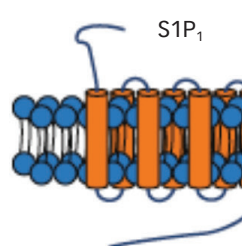

Location

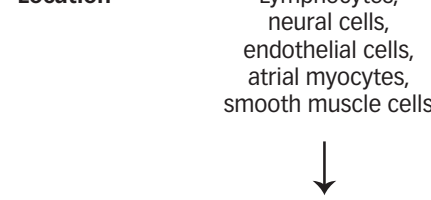

Function

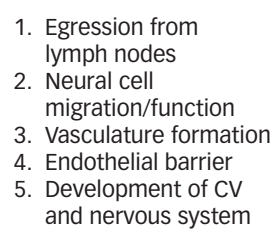

1. Endothelial barrer

2. Vascular tone

3. Hearing and balance

Central nervous system smooth muscle cells

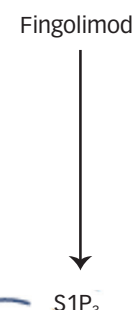

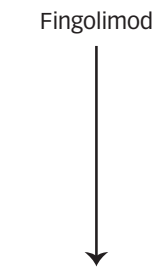

Fingolimod

Siponimod

Ozanimod

Ceralifimod

GSK2018682
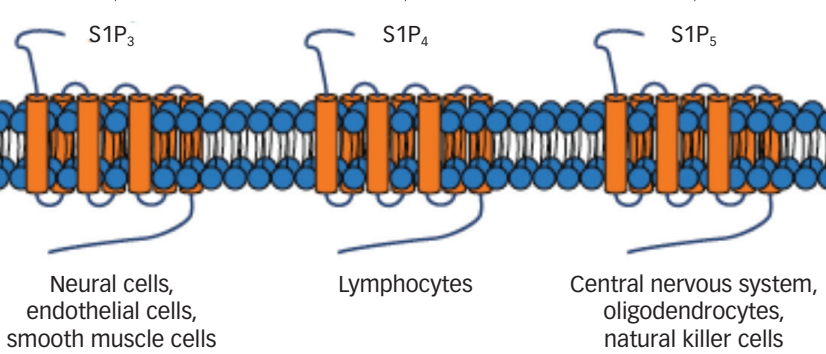

smooth muscle cells
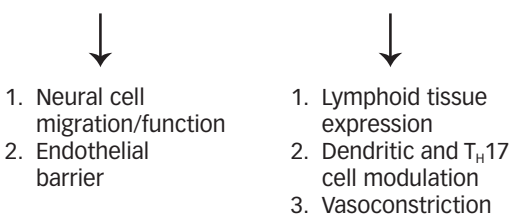

1. Oligodendrocyte function

2. Natural killer cell migration

A: Binding of S1P receptor modulators to S1P, on central memory T-cellS. B: Interaction of S1P receptor modulators with S1P receptor subtypes. C: Interaction of fingolimod and selective S1P receptor drugs with S1P receptor subtypes. ${ }^{a}$ Amiselimod is selective, but its selectivity is unknown. CCR7 =C-C chemokine receptor type 7; CV = cardiovascular; $S 1 P=$ sphingosine-1-phosphate; $S 1 P_{1-5}=$ sphingosine-1-phosphate receptor subtypes $1-5 ; T_{H} 17=T$ helper cell $17 ; T_{\mathrm{CM}}=$ central memory $T$-cell; $T_{\mathrm{EM}}=$ effector memory $T$-cell; $T_{N}=$ naive T-cell. Reproduced from Comi et al., $2017^{11}$ with permission from the original sources. ${ }^{54,55}$

Therefore, TCM do not leave the lymph node in response to S1P signals. As a result, fewer circulating lymphocytes are available to infiltrate the CNS and mount an autoimmune reaction on the axon myelin sheath. ${ }^{8,12,13}$ Modulators of the S1P receptor prevent these autoreactive cells from migrating into the CNS. By contrast, the levels of peripheral effector memory T-cells (TEM) are mostly unaffected by S1P receptor modulators, preserving immunosurveillance and the ability to respond to and contain locally invading pathogens. ${ }^{11}$

Fingolimod (Gilenya ${ }^{\oplus}$, Novartis, Basel, switzerland) is a lipophilic sphingosine-like agent that is phosphorylated by SphK1/2 to become fingolimod-P, an S1P analogue. Fingolimod-P binds to the S1P 1 receptor and is internalised in the same way as S1P, but the receptor is then degraded, preventing cell surface signalling. ${ }^{8}$ Fingolimod is an agonist of four S1P receptor subtypes $\left(\mathrm{S}_{1} \mathrm{P}_{1}, \mathrm{~S}_{1} \mathrm{P}_{3}, \mathrm{~S}_{1} \mathrm{P}_{4} \text { and } \mathrm{S}_{1} \mathrm{P}_{5}\right)^{14}$ and induces immunosuppression through inhibition of recirculation of naïve T-cells and the release of antigen-activated T-cells from the draining lymph nodes to lymph and to the blood compartment. ${ }^{15}$ It crosses the blood-brain barrier and may have direct CNS effects, distinguishing it from immunologically targeted MS therapies, although this has not been demonstrated in humans. ${ }^{13}$ Fingolimod has also been found to attenuate neuroinflammation in rats by regulating the activation and neuroprotective effects of microglia, mainly via S1P $1_{1} \cdot 1,17$ Fingolimod also has direct CNS effects via suppression of pathogenic astrocyte 
Table 1: Summary of sphingosine-1-phosphate receptor modulator pharmacokinetics and pharmacodynamics

\begin{tabular}{|c|c|c|c|c|c|c|c|}
\hline & $\begin{array}{l}\text { Receptor } \\
\text { selectivity }\end{array}$ & $\begin{array}{l}\text { Pro-drug } \\
\text { (requires } \\
\text { phosphorylation in vivo) }\end{array}$ & $T_{\max }(\mathrm{h})$ & $\begin{array}{l}\text { Time to } \\
\text { Iymphocyte count } \\
\text { reduction (h) }\end{array}$ & $\begin{array}{l}\text { Lymphocyte } \\
\text { decrease from } \\
\text { baseline (\%) }\end{array}$ & $T_{1 / 2}(\mathrm{~h})$ & $\begin{array}{l}\text { Time to lymphocyte count } \\
\text { recovery after treatment } \\
\text { discontinuation (days) }\end{array}$ \\
\hline Fingolimod ${ }^{14,32}$ & $\begin{array}{l}\mathrm{S}_{1} \mathrm{P}_{1} \\
\mathrm{~S}_{1} \\
\mathrm{~S}_{3} \\
\mathrm{~S}_{4} \\
\mathrm{PP}_{5}\end{array}$ & Yes & $12-16$ & $4-6$ & 70 & $144-216$ & $30-60$ \\
\hline Ponesimod ${ }^{39,40}$ & $\mathrm{~S}_{1} \mathrm{P}_{1}$ & No & $2-4$ & 6 & $50-70$ & 30 & 7 \\
\hline Siponimod 48 & $\begin{array}{l}\mathrm{S}_{1 \mathrm{P}_{1}} \\
\mathrm{~S}_{1} \mathrm{P}_{5}\end{array}$ & No & $3.0-4.5$ & $4-6$ & $33-76$ & 30 & $1-5$ \\
\hline Ozanimod ${ }^{42}$ & $\begin{array}{l}\mathrm{S}_{1 \mathrm{P}_{1}} \\
\mathrm{~S}_{1} \mathrm{P}_{5}\end{array}$ & No & $6-8$ & $6-12$ & $34-68$ & $17-21$ & $2-3$ \\
\hline Amiselimod 46,47 & $\begin{array}{l}\mathrm{S}_{1} \mathrm{P}_{1} \\
\mathrm{~S}_{1} \mathrm{P}_{5}\end{array}$ & Yes & $12-16$ & No data & $60-66$ & $380-420$ & 49 \\
\hline
\end{tabular}

$h=$ hour; $S_{1 P_{1-5}}=$ sphingosine-1-phosphate receptor subtypes $1-5 ; T_{1 / 2}=$ elimination half life; $T_{\max }=$ time to maximum plasma concentration.

activation..$^{18}$ While the therapeutic action of fingolimod is largely a result of its binding to $\mathrm{S}_{1} \mathrm{P}_{1}$, its modulation of $\mathrm{S}_{1} \mathrm{P}_{3}, \mathrm{~S}_{1} \mathrm{P}_{4}$ and $\mathrm{S}_{1} \mathrm{P}_{5}$ has been associated with AES

\section{Clinical efficacy and safety of fingolimod}

Fingolimod has demonstrated efficacy and safety in three large phase III studies. In the FTY720 Research Evaluating Effects of Daily Oral therapy in Multiple Sclerosis (FREEDOMS) study $(n=1,033)$, over 24 months, fingolimod decreased annualised relapse rate (ARR) by over $50 \%$, as well as reducing the risk of disability progression compared with placebo in patients with RMS. ${ }^{19}$ These findings were confirmed in the FREEDOMS $\|$ study $^{20}$ and the TRial Assessing injectable interferoN vS FTY720 Oral in RRMS (TRANSFORMS) trial $(n=1,153)$, in which fingolimod demonstrated superior efficacy to intramuscular interferon beta-1a (IFN $\beta$-1a) in patients with RMS, although there was no difference between fingolimod and IFN $\beta$-1a in terms of disability progression. ${ }^{21}$ In 2010, the US Food and Drug Administration (FDA) approved fingolimod as the first oral DMT to treat RMS. ${ }^{22}$

Compliance with fingolimod has been shown to be superior to injected and infused DMTs. ${ }^{23,24}$ In recently presented data from the phase III Safety and Efficacy of Fingolimod in Pediatric Patients With Multiple Sclerosis (PARADIGMS) study ( $n=190)$, fingolimod resulted in a clinically meaningful, statistically significant reduction in the ARR of paediatric RMS patients compared with IFN $\beta$-1a injections. ${ }^{25,26}$ Another recently published study, Fingolimod on cognitive symptoms and brain atrophy (GOLDEN), found positive effects of fingolimod in cognitive, magnetic resonance imaging (MRI), and clinical outcomes in 157 patients with RMS over 18 months. ${ }^{27}$ However, fingolimod is not effective in all forms of MS; in the phase III Oral fingolimod in primary progressive multiple sclerosis (INFORMS) study $(n=970)$ it did not slow disease progression. ${ }^{28}$

Despite a growing body of clinical evidence supporting the efficacy of fingolimod, ${ }^{11}$ its clinical use has been limited by safety concerns with respect to cardiac effects, infections and macular oedema.. ${ }^{29}$ However, cardiac symptoms, including bradycardia and atrioventricular conduction block on drug initiation, are transient. ${ }^{21} \mathrm{~A}$ number of factors should be considered before initiation of fingolimod or require monitoring while on treatment, including first-dose monitoring, pregnancy, diabetes mellitus, posterior reversible encephalopathy syndrome, basal cell carcinoma, infections such as varicella, opportunistic cryptococcal infections and progressive multifocal leukoencephalopathy (PML). ${ }^{11}$ These cardiac effects are due to activation of $\mathrm{S1P}_{1}$ on cardiac myocytes, which

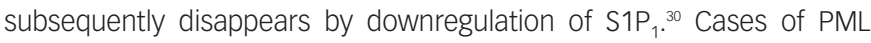
have been reported, ${ }^{31,32}$ but the estimated risk is considered low, based on experience to date with fingolimod. ${ }^{33}$ There is also a need for regular dermatological follow-up because of the slightly increased risk of basal cell carcinomas. ${ }^{32}$ Studies assessing the long-term safety and efficacy of fingolimod are currently ongoing; to date, no new safety signals have been observed. ${ }^{34}$

The use of selective S1P modulators may overcome these safety concerns. Unlike fingolimod, which suppresses lymphocyte recirculation

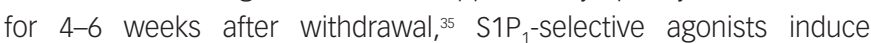
reversible lymphopaenia while persisting in the CNS and are therefore less likely to activate latent infections. ${ }^{36}$

\section{Selective sphingosine-1-phosphate receptor modulators}

Following the approval of fingolimod, a number of selective S1P modulators entered clinical development (Table 1) and several are currently being evaluated in phase III clinical studies (Table 2). These agents differ in their selectivity and activation potency $\left(\mathrm{EC}_{50}\right)$. $^{30,37,38}$ The therapeutic effects of these compounds are caused by rapid internalisation, degradation and functional antagonism of $\mathrm{S}_{1} \mathrm{P}_{1}$, leading to lymphocyte sequestration in the lymph nodes. ${ }^{11}$ Since they

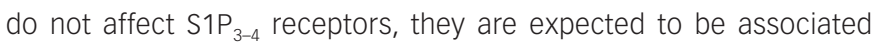
with fewer AEs, including those occurring after the first dose. In contrast to the long half-life and slow elimination of fingolimod, all of the selective $\mathrm{S}_{1} \mathrm{P}_{1}$ modulators in clinical development (apart from amiselimod) have a shorter half-life and show a reduced time to lymphocyte recovery after treatment discontinuation compared with fingolimod, which is an important consideration for patients who need to interrupt medication. ${ }^{11}$

\section{Ponesimod}

Ponesimod (Actelion, Basel, Switzerland) is an orally active selective $\mathrm{S}_{1} \mathrm{P}_{1}$

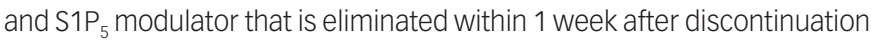
and its pharmacological effects are rapidly reversible. ${ }^{39}$ Ponesimod

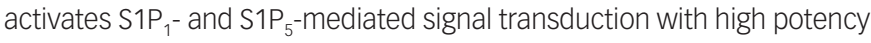
and selectivity. ${ }^{37}$ The quicker elimination of ponesimod may be an advantage in managing serious or opportunistic infections and may also help to prevent complications in case of AEs such as macular oedema, pulmonary function changes and liver enzyme elevations. 
Table 2: Summary of clinical studies of sphingosine-1-phosphate receptor modulators

\begin{tabular}{|c|c|c|c|}
\hline Drug & Clinical trial details & Efficacy findings & Safety findings \\
\hline Ponesimod & $\begin{array}{l}\text { Phase IIb, n=464, } \\
24 \text { weeks, RMS }\end{array}$ & $\begin{array}{l}\text { Mean cumulative number of new T1 Gd+ lesions at weeks } \\
12-24 \text { was lower in ponesimod } 10 \mathrm{mg}(3.5 ; \mathrm{RR} 0.57 ; \mathrm{p}=0.0318) \text {, } \\
20 \mathrm{mg}(1.1 ; \mathrm{RR} 0.17 ; \mathrm{p}<0.0001) \text { and } 40 \mathrm{mg}(1.4 ; \mathrm{RR} 0.23 \text {; } \\
\text { p<0.0001) compared with placebo (6.2). Mean ARR was 53\% } \\
\text { lower with } 40 \mathrm{mg} \text { ponesimod versus placebo, (0.25 versus } \\
0.53 ; p=0.0363) \text {. Time to first confirmed relapse increased with } \\
\text { ponesimod compared with placebo. }\end{array}$ & $\begin{array}{l}\text { Proportions of patients who had } \geq 1 \text { AE during the treatment } \\
\text { period were similar across all ponesimod groups (73.9-77.2\%) } \\
\text { and placebo (74.4\%). Frequent TEAEs with a higher incidence } \\
\text { in ponesimod groups were anxiety, dizziness, dyspnoea, } \\
\text { increased ALT, influenza, insomnia and peripheral oedema. } \\
\text { Some cardiac and respiratory TEAEs, but all resolved on } \\
\text { treatment discontinuation. }\end{array}$ \\
\hline Ozanimod & $\begin{array}{l}\text { Phase III, } \mathrm{n}=1,313 \text {, } \\
24 \text { weeks, } \mathrm{RMS}^{44}\end{array}$ & $\begin{array}{l}\text { Significant reduction in ARR for ozanimod } 1 \mathrm{mg}(0.17 \text {, } \\
\mathrm{p}<0.0001) \text { and } 0.5 \mathrm{mg}(0.22, \mathrm{p}=0.0168) \text { compared with IFN } \beta-1 \mathrm{a} \\
\text { (0.28). Significant reduction in new or enlarging T2 lesions for } \\
\text { ozanimod } 1 \mathrm{mg}(42 \%, \mathrm{p}<0.0001) \text { and } 0.5 \mathrm{mg}(35 \%, \mathrm{p}=0.0001) \\
\text { compared with IFN } \beta-1 \mathrm{a} \text {, as well as a significant reduction } \\
\text { in Gd+ MRI lesions for ozanimod } 1 \mathrm{mg}(53 \%, p=0.0006) \text { and } \\
\text { ozanimod } 0.5 \mathrm{mg}(47 \%, p=0.0030) \text {. Reduction in BV loss of } \\
27 \% \text { with } 1 \mathrm{mg} \text { ozanimod }(p<0.0001) \text { and } 25 \% \text { in } 0.5 \mathrm{mg} \text { group } \\
(\mathrm{p}<0.0001) \text {. }\end{array}$ & $\begin{array}{l}\text { Three serious TEAEs were reported in patients assigned } \\
\text { ozanimod } 0.5 \text { mg: optic neuritis, somatoform autonomic } \\
\text { dysfunction and cervical squamous metaplasia (HPV-related). } \\
\text { No serious infectious or cardiac AEs were reported, and no } \\
\text { cases of macular oedema. The most common TEAEs in the } \\
\text { ozanimod } 0.5 \text { mg and } 1 \mathrm{mg} \text { groups compared with placebo } \\
\text { were nasopharyngitis ( } 11 \text { and } 5 \text { versus 12), headache ( } 5 \text { and } \\
5 \text { versus } 8 \text { ), and urinary-tract infections (6 and } 2 \text { versus } 2 \text { ). } \\
\text { No clinically relevant cases of bradycardia, AVB or sinus pause } \\
\text { with ozanimod. }\end{array}$ \\
\hline Ozanimod & $\begin{array}{l}\text { Phase III (SUNBEAM) } \\
n=1,346, \text { mean } \\
13.6 \text { months, RMS }\end{array}$ & $\begin{array}{l}\text { Both ozanimod } 0.5 \text { and } 1 \mathrm{mg} \text { treatment groups had statistically } \\
\text { significant reductions in ARR compared with IFN } \beta-1 \mathrm{a} \text {. } \\
\text { Significant reduction in number of new or enlarging T2 lesions } \\
\text { and the adjusted mean number of Gd+ at month } 12 \text { for both } \\
\text { ozanimod groups compared with IFN } \beta-1 \mathrm{a} \text {. }\end{array}$ & $\begin{array}{l}\text { Rate of discontinuation due to AEs was also low and similar } \\
\text { across treatment groups. No first dose, clinically relevant cases } \\
\text { of bradycardia and no AVB of second degree or higher } \\
\text { were reported. }\end{array}$ \\
\hline Amiselimod & $\begin{array}{l}\text { Phase } \|, n=415 \\
24 \text { weeks, } \text { RMS }^{46}\end{array}$ & 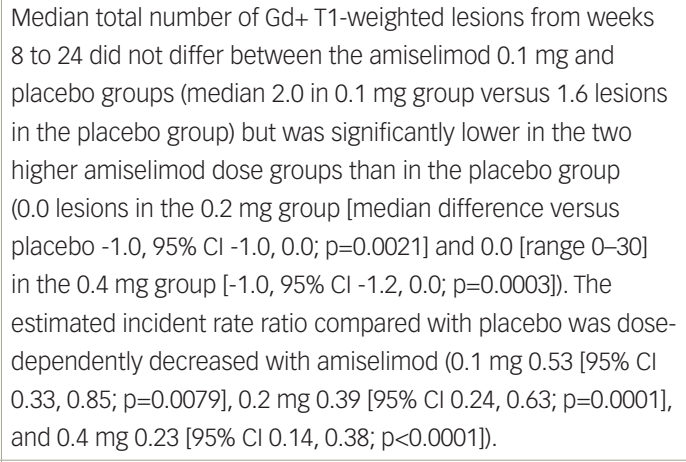 & $\begin{array}{l}\text { Incidence of TEAEs including infections and cardiac disorders, } \\
\text { were similar in the amiselimod treatment groups (56\%) in } \\
\text { the } 0.1 \mathrm{mg} \text { group of } 105 \text { patients, } 67 \% \text { in the } 0.2 \mathrm{mg} \text { group } \\
\text { of } 103 \text { patients, and } 56 \% \text { of } 104 \text { patients in the } 0.4 \mathrm{mg} \text { group } \\
\text { compared with the incidence in the placebo group ( } 64 \% \text { of } 103 \\
\text { patients); the most common TEAEs were headache (10\%, 10\%, } \\
10 \% \text { versus } 4 \% \text { ) and nasopharyngitis ( } 9 \%, 7 \%, 10 \% \text { versus } 8 \%) \text {. } \\
\text { No serious TEAEs reported for more than one patient in any } \\
\text { group and no clinically significant heart rate reduction at any } \\
\text { amiselimod dose. }\end{array}$ \\
\hline Siponimod & $\begin{array}{l}\text { Phase III, } n=1,651 \text {, } \\
3 \text { months, SPMS }{ }^{49}\end{array}$ & $\begin{array}{l}\text { Siponimod reduced the risk of } 3 \text {-month CDP by } 21 \% \text { versus } \\
\text { placebo ( } p=0.013) \text {. RR for T25FW observed for siponimod was } \\
6.2 \% \text { and not statistically significant ( } p=0.440) \text {. Siponimod } \\
\text { reduced the risk of 6-month CDP by } 26 \%(p=0.006) \text {, ARR by } \\
55.5 \% \text { ( } p<0.0001) \text {, } T 1 \text { Gd+ lesion number by } 86.6 \%(p<0.0001) \text {, } \\
\text { and new T2 lesion number by } 81 \% \text { ( } p<0.0001) \text {. }\end{array}$ & $\begin{array}{l}\text { At least one TEAE in } 88.7 \% \text { of siponimod group and } 81.5 \% \\
\text { of placebo group. More heart rate and conduction AES, } \\
\text { hypertension, macular oedema, and convulsions in the } \\
\text { treatment than in the placebo group. Incidence of infections } \\
\text { was similar between groups, except for an increased } \\
\text { herpes zoster incidence in the treatment group. No cases } \\
\text { of opportunistic infections, including PML, and no increased } \\
\text { incidence of malignancies. }\end{array}$ \\
\hline
\end{tabular}

$A E S=$ adverse events; $A L T=$ alanine aminotransferase $; A R R=$ annualised relapse rate; $A V B=$ atrioventricular blocks; $B V=$ brain volume; $C D P=$ confirmed disability progression; $\mathrm{Cl}=$ confidence interval; $\mathrm{Gd}+=$ gadolinium; $\mathrm{HPV}=$ human papillomavirus; IFN $\beta$-1a = interferon beta $1 \mathrm{a} ; \mathrm{MRI}=$ magnetic resonance imaging; $P M L=$ progressive multifocal leukoencephalopathy; $R M S$ = relapsing multiple sclerosis; $R R=$ risk ratio; SPMS = secondary progressive multiple sclerosis; TEAE = treatment-emergent adverse event; T25FW = timed 25-foot walk

In a double-blind, placebo-controlled, dose-finding phase IIb study $(\mathrm{n}=464)$, once-daily treatment with ponesimod 10,20 or $40 \mathrm{mg}$ significantly reduced the number of new $\mathrm{T} 1$ gadolinium enhancing $(\mathrm{Gd}+)$ lesions and ARR, as well as increasing the time to first confirmed relapse compared with placebo in patients with RMS ${ }^{40}$ In all ponesimod groups, the majority of AEs were mild or moderate in intensity and the proportions of patients who had one or more AE during the treatment period were similar across all ponesimod and placebo groups. Frequently reported treatment emergent AEs (TEAEs) with a higher incidence in the ponesimod groups compared with placebo were anxiety, dizziness, dyspnoea, increased alanine aminotransferase (ALT), influenza, insomnia and peripheral oedema. Incidences of dyspnoea and peripheral oedema appeared to be dose related, with substantially more cases reported in the ponesimod $40 \mathrm{mg}$ group compared with the ponesimod 10 and $20 \mathrm{mg}$ groups. During the treatment period, a total of 27 serious AEs (excluding hospitalisations for MS relapse) were reported. These included two malignancies: one in the ponesimod $10 \mathrm{mg}$ group and one in the placebo group. Cardiac AEs associated with ponesimod treatment initiation included first-degree and second-degree atrioventricular block (AVB) and bradycardia. All AES relating to heart rate and rhythm occurred on day 1; there was no need for intervention and no recurrence of these AEs later during treatment. Among patients receiving ponesimod who discontinued due to cardiac AEs, $2.6 \%$ required treatment compared with none in the placebo group. The proportion of patients with one or more infection-associated AE was similar across the four groups. There were no treatment discontinuations due to lymphopaenia. The proportion of patients with one or more respiratory AE was higher in the ponesimod 
than in the placebo group (ponesimod $10 \mathrm{mg}$, 9.3\%; ponesimod $20 \mathrm{mg}$, 16.7\%; ponesimod $40 \mathrm{mg}, 31.9 \%$; placebo, 6.6\%), leading to premature discontinuation of ponesimod in seven patients. The onset of dyspnoea usually occurred within the first month of treatment; all cases resolved. A dose-dependent decrease in forced expiratory volume in 1 second (FEV1) was also observed with ponesimod treatment. ${ }^{40}$

In a small study ( $\mathrm{n}=16$ ) in healthy subjects, ponesimod treatment led to a marked reduction in overall $\mathrm{T}$ - and $\mathrm{B}$-cells, with a dramatic reduction in the number of CD4+ cells, whereas CD8+ and natural killer (NK) cells were less affected. ${ }^{41} \mathrm{~A}$ phase III study is currently ongoing to investigate the efficacy and safety of ponesimod in 1,100 patients with RMS (NCT02425644). The primary objective of the trial is to assess whether ponesimod is superior to teriflunomide in reducing the ARR over 108 weeks. This study will be the first to compare the efficacy and safety of two oral treatments in RMS patients. Another ongoing phase III study, the Clinical Study to Compare the Efficacy and Safety of Ponesimod to Placebo in Subjects With Active Relapsing Multiple Sclerosis Who Are Treated With Dimethyl Fumarate (Tecfidera ${ }^{\oplus}$ ) (POINT) is evaluating ponesimod as add-on therapy with dimethylfumarate (DMF) in patients in patients who have received DMF for at least 6 months prior to commencing the study (NCT02907177).

\section{Ozanimod}

Ozanimod (formally RPC1063, Celgene) is an orally active selective S1 $\mathrm{P}_{1}$ and $\mathrm{S}_{1} \mathrm{P}_{5}$ modulator that induces lymphopaenia and regulates immune response. ${ }^{38,42}$ It was evaluated in a phase $\| / / I I$ randomised, multicentre trial ( $n=258)$, Efficacy and Safety Study of RPC1063 in Relapsing Multiple Sclerosis Patients (RADIANCE). The number of $\mathrm{Gd}+$ enhancing lesions were significantly lower with ozanimod compared with placebo. ${ }^{43}$

Two recent phase III studies have evaluated two doses of oral ozanimod compared with IFN $\beta$-1a in people with relapsing-remitting MS (RRMS). The RADIANCE Part B study compared two doses (1.0 mg and $0.5 \mathrm{mg}$ ) of oral ozanimod with IFN $\beta$-1a in 1,313 patients with RMS. Two-year findings showed significant reduction in ARR for ozanimod $1.0 \mathrm{mg}$ ( $A R R=0.17, p<0.0001)$ and $0.5 \mathrm{mg}(\mathrm{ARR}=0.22, p=0.0168)$ compared with IFN $\beta$-1a (ARR=0.28). ${ }^{44}$ There was also a significant reduction in new or enlarging T2 lesions for ozanimod $1.0 \mathrm{mg}(42 \%, \mathrm{p}<0.0001)$ and $0.5 \mathrm{mg}(35 \%, \mathrm{p}=0.0001)$ compared with IFN $\beta-1$ a, as well as a significant reduction in $\mathrm{Gd}+\mathrm{MRI}$ lesions for ozanimod $1.0 \mathrm{mg}(53 \%, \mathrm{p}=0.0006)$ and ozanimod $0.5 \mathrm{mg}(47 \%, p=0.0030)$ compared with IFN $\beta-1 \mathrm{a}$. A total of $75 \%$ of patients taking ozanimod $1.0 \mathrm{mg}, 74 \%$ taking ozanimod $0.5 \mathrm{mg}$ and $83 \%$ taking IFN $\beta$-1a reported TEAES. The majority were mild; the most common AEs across all treatment groups were nasopharyngitis, headache, increased ALT, influenza-like illness, hypertension, increased gamma-glutamyl transferase, pharyngitis and urinary tract infection. Incidences of ALT increase were low, transient and generally resolved without study drug discontinuation. The overall incidence of serious AEs was low and similar across treatment arms. Discontinuation of study drug due to AEs occurred in $3.0 \%$ of the ozanimod $1.0 \mathrm{mg}$ group, $3.2 \%$ for ozanimod $0.5 \mathrm{mg}$ and $4.1 \%$ for IFN $\beta$-1a. No second degree or higher AVBS were observed. Serious cardiac AEs occurred in $0.0 \%$ for ozanimod $1.0 \mathrm{mg}$, 0.7\% for ozanimod $0.5 \mathrm{mg}$ and $0.5 \%$ for IFN $\beta-1$ a groups. Infection rates were similar across treatment arms; serious infection rates were low and similar across treatment arms, with no serious opportunistic infections.

Recently, positive results were announced from the phase III Study of RPC1063 in Relapsing MS (SUNBEAM, $n=1,346$ ). ${ }^{45}$ Both ozanimod 0.5 and $1.0 \mathrm{mg}$ treatment groups demonstrated statistically significant reductions compared with IFN $\beta$-1a in ARR. The number of new or enlarging T2 lesions and the adjusted mean number of $\mathrm{Gd}+$ at month 12 demonstrated a significant reduction for both ozanimod groups compared with IFN $\beta-1$. The rate of discontinuation due to AEs was also low and similar across treatment groups. No first dose, clinically relevant cases of bradycardia and no AVB of second degree or higher were reported.

\section{Amiselimod}

Amiselimod (formerly MT-1303, Mitsubishi Tanabe Pharma, Japan) is a

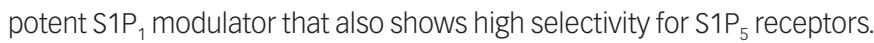
In a phase II trial of patients $(n=415)$ with active RRMS, amiselimod $0.2 \mathrm{mg}$ and $0.4 \mathrm{mg}$ significantly reduced the total number of $\mathrm{Gd}+$ T1-weighted lesions after 24 weeks of treatment (patients treated with $0.1 \mathrm{mg}$ amiselimod had a similar number of these lesions compared with the placebo group). ARRs were lower with amiselimod 0.2 and $0.4 \mathrm{mg}$ than with placebo, although the difference was significant only in the $0.4 \mathrm{mg}$ group $(\mathrm{n}=104)$. Brain volume loss was similar in the amiselimod and placebo groups, although reductions in grey matter volume were significantly smaller with all amiselimod doses than with placebo $(n=103) .{ }^{46}$ The incidence of TEAEs, including infections and cardiac disorders, were similar in the amiselimod treatment groups (56\% of the $0.1 \mathrm{mg}$ group, $67 \%$ of the $0.2 \mathrm{mg}$ group, and $56 \%$ of the $0.4 \mathrm{mg}$ group) to the incidence in the placebo group (64\%); the most common TEAES were headache and nasopharyngitis. No serious TEAE was reported for more than one patient in any group and no clinically significant heart rate reduction was observed at any amiselimod dose. ${ }^{46} \mathrm{~A}$ recent study found that amiselimod showed high potency with minimal cardiac effects at the anticipated clinical dose and is unlikely to require dose titration. ${ }^{47}$

\section{Siponimod}

Siponimod (Novartis, Basel, Switzerland) is a novel alkoxyimino derivative that binds to both $\mathrm{S}_{1} \mathrm{P}_{1}$ and $\mathrm{S}_{\mathrm{P}} \mathrm{P}_{5}$. Its half-life is relatively short, allowing for fast immune reconstitution. ${ }^{48}$ Its efficacy and safety was investigated versus placebo in the phase III Exploring the Efficacy and Safety of Siponimod in Patients With Secondary Progressive Multiple Sclerosis (EXPAND) study in 1,651 patients with SPMS, a condition for which treatment options are limited. Siponimod reduced the risk of 3-month confirmed disability progression (CDP) by $21 \%$ versus placebo (hazard ratio $[H R]: 0.79 ; p=0.013)$. Siponimod also reduced the risk of 6-month CDP by $26 \%(p=0.006)$, ARR by $55.5 \%$ ( $p<0.0001)$, T1 Gd+ lesion number by $86.6 \%(p<0.0001)$ and new 12 lesion number by $81 \%$ $(p<0.0001) .{ }^{49}$ At least one TEAE was reported in $88.7 \%$ in the siponimod group and $81.5 \%$ in the placebo group. The incidence of heart rate and conduction AEs, hypertension, macular oedema and convulsions was higher in the treatment than in the placebo group. The incidence of infections was similar between groups, except for a higher incidence of herpes zoster in the treatment group. There were no cases of opportunistic infections, including PML, and no increased incidence of malignancies, including skin cancers. ${ }^{49}$

\section{Discontinued sphingosine-1-phosphate 1 agents}

Although successful in phase II clinical trials, clinical development of the $\mathrm{S} 1 \mathrm{P}_{1}$ modulator ceralifimod (Merck KGaA, Darmstadt, Germany) ) $^{50}$ was halted after the premature discontinuation of a phase III study. Clinical development of CS- $0777^{51}$ and GSK2018682 for MS reached phase I stage but appears to have been discontinued since..$^{52}$ Possible reasons are competition from emerging therapies.

\section{Summary and concluding remarks}

The discovery of the ability of S1P receptors and their modulators to block immune cell trafficking led to the regulatory approval of fingolimod, the first orally active drug treating RMS. This has stimulated research into 
more selective S1P receptors, which have improved pharmacodynamics and are less likely to cause off-target AEs than fingolimod. These include selective S1P $\mathrm{P}_{1}$ modulator (ponesimod) and dual agonists on S1P 1 and

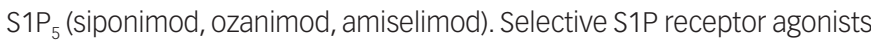
offer a convenient alternative to other MS drugs that are associated with broad immune suppression, as well as the potential for benefit in a number of autoimmune and inflammatory conditions such as psoriasis,
Crohn's disease, ulcerative colitis, polymyositis, dermatomyositis, liver failure, renal failure, acute stroke and transplant rejection..$^{53}$ While long-term safety data of selective S1P receptor agonists are needed, the growing body of such data on the efficacy and safety of fingolimod is reassuring. It is likely that, in the near future, more S1P receptor modulators will be approved for the treatment of MS and other disorders associated with autoimmunity and inflammation.
1. Torkildsen $\mathrm{O}$, Myhr KM, Bo L. Disease-modifying treatments for multiple sclerosis - a review of approved medications. Eur J Neurol. 2016;23 Suppl 1:18-27.

2. Cox D, Stone J. Managing self-injection difficulties in patients with relapsing-remitting multiple sclerosis. J Neurosci Nurs. 2006;38:167-71.

3. Samuel L, Lowenstein EJ. Recurrent injection site reactions from interferon beta 1-b. J Drugs Dermatol. 2006;5:366-7.

4. Hemmer B, Hartung HP. Toward the development of rational therapies in multiple sclerosis: what is on the horizon? Ann Neurol. 2007;62:314-26.

5. Nath A, Berger JR. Complications of immunosuppressive/ immunomodulatory therapy in neurological diseases. Curr Treat Options Neurol. 2012:14:241-55.

6. Tur C, Montalban X. Progressive MS trials: lessons learned. Mult scler. 2017:23:1583-92.

7. Montalban X, Hauser SL, Kappos L, et al. Ocrelizumab versus placebo in primary progressive multiple sclerosis. N Eng/ J Med. 2017;376:209-20.

8. Subei AM, Cohen JA. Sphingosine 1-phosphate receptor modulators in multiple sclerosis. CNS Drugs. 2015;29:565-75

9. Groves A, Kihara Y, Chun J. Fingolimod: direct CNS effects of sphingosine 1-phosphate (S1P) receptor modulation and implications in multiple sclerosis therapy. J Neurol SC. 2013;328:9-18.

10. Mandala S, Hajdu R, Bergstrom J, et al. Alteration of lymphocyte trafficking by sphingosine-1-phosphate receptor agonists science. 2002:296:346-9.

11. Comi $G$, Hartung HP, Bakshi R, et al. Benefit-risk profile of sphingosine-1-phosphate receptor modulators in relapsing and secondary progressive multiple sclerosis. Drugs. 2017:77:1755-68.

12. Adachi K, Chiba K. FTY720 story. Its discovery and the following accelerated development of sphingosine 1-phosphate receptor agonists as immunomodulators based on reverse pharmacology. Perspect Medicin Chem. 2007;1:11-23.

13. Chun J, Hartung HP. Mechanism of action of oral fingolimod (FTY720) in multiple sclerosis. Clin Neuropharmacol. 2010;33:91-101

14. Brinkmann $\mathrm{V}$, Davis $\mathrm{MD}$, Heise $\mathrm{CE}$, et al. The immune modulator FTY720 targets sphingosine 1-phosphate receptors. J Biol Chem 2002:277:21453-7.

15. Xie JH, Nomura N, Koprak SL, et al. Sphingosine-1-phosphate receptor agonism impairs the efficiency of the local immune response by altering trafficking of naive and antigen-activated CD4+ T cells. J Immunol. 2003:170:3662-70.

16. Jackson SJ, Giovannoni G, Baker D. Fingolimod modulates microglial activation to augment markers of remyelination. J Neuroinflammation. 2011;8:76.

17. Noda $H$, Takeuchi H, Mizuno T, et al. Fingolimod phosphate promotes the neuroprotective effects of microglia. J Neuroimmunol. 2013;256:13-8.

18. Choi JW, Gardell SE, Herr DR, et al. FTY720 (fingolimod) efficacy in an animal model of multiple sclerosis requires astrocyte sphingosine 1-phosphate receptor 1 (S1P1) modulation. Proc Natl Acad Sci U S A. 2011;108:751-6.

19. Kappos $L$, Radue EW, O'Connor P, et al. A placebo-controlled trial of oral fingolimod in relapsing multiple sclerosis. N Eng/ Med. 2010;362:387-401.

20. Calabresi PA, Radue EW, Goodin D, et al. Safety and efficacy of fingolimod in patients with relapsing-remitting multiple sclerosis (FREEDOMS II): a double-blind, randomised, placebocontrolled, phase 3 trial. Lancet Neurol. 2014;13:545-56.

21. Cohen JA, Barkhof F, Comi G, et al. Oral fingolimod or intramuscular interferon for relapsing multiple sclerosis. N Eng/ J Med. 2010;362:402-15.
22. US Food and Drug Administration (FDA). Approval letter: Gilenya (fingolimod). Available at: www.accessdata.fda.gov/ drugsatfda_docs/nda/2010/022527Orig1s000ltr.pdf (accessed 9 November 2017)

23. Agashivala N, Wu N, Abouzaid S, et al. Compliance to fingolimod and other disease modifying treatments in multiple sclerosis patients, a retrospective cohort study. BMC Neurol. 2013;13:138.

24. Bergvall N, Petrilla AA, Karkare SU, et al. Persistence with and adherence to fingolimod compared with other diseasemodifying therapies for the treatment of multiple sclerosis: modirying therapies for the treatment of multiple sclerosis: 2014;17:696-707.

25. Chitnis T, Arnold DL, Banwell B, et al. PARADIGMS: a randomised double-blind study of fingolimod versus interferon beta-1a in paediatric multiple sclerosis. Presented at: MS Paris 2017,
7th Joint ECTRIMS-ACTRIMS meeting. 28 October 2017, Paris, 7th Joint ECTRIMS-ACT
France. Abstr. \#276.

26. Novartis. Novartis landmark Phase III trial shows fingolimod significantly reduces relapses in children and adolescents with MS. Available at: www.novartis.com/news/mediareleases/novartis-landmark-phase-iii-trial-shows-fingolimodsignificantly-reduces (accessed 29 January 2018)

27. Comi G, Patti F, Rocca MA, et al. Efficacy of fingolimod and interferon beta-1 $\mathrm{b}$ on cognitive, MRI, and clinical outcomes in relapsing-remitting multiple sclerosis: an 18-month, open-label, rater-blinded, randomised, multicentre study (the GOLDEN study). J Neurol. 2017;264:2436-49.

28. Lublin F, Miller DH, Freedman MS, et al. Oral fingolimod in primary progressive multiple sclerosis (INFORMS): a phase 3 randomised, double-blind, placebo-controlled trial. 2016:387:1075-84.

29. Willis MA, Cohen JA. Fingolimod therapy for multiple sclerosis Semin Neurol. 2013;33:37-44

30. Camm J, Hla T, Bakshi R, et al. Cardiac and vascular effects of fingolimod: mechanistic basis and clinical implications. Am Heart J. 2014;168:632-44.

31. US Food and Drug Administration (FDA). FDA Drug Safety Communication: FDA warns about cases of rare brain infection with MS drug Gilenya (fingolimod) in two patients with no prio exposure to immunosuppressant drugs. Available at: www.fda. gov/downloads/Drugs/Drugsafety/UCM457120.pdf (accessed 28 March 2018)

32. European Medicines Agency (EMA). Gilenya. Summary of product characteristics. Available at: www.ema.europa.eu/ docs/en_GB/document_library/EPAR - Product_Information/ human/002202/WC500104528.pdf (accessed 13 December 2017).

33. Yoshii F, Moriya Y, Ohnuki T, et al. Neurological safety of fingolimod: an updated review. Clin Exp Neuroimmunol. 2017;8:233-43.

34. Kappos L, O'Connor P, Radue EW, et al. Long-term effects of fingolimod in multiple sclerosis: the randomized FREEDOMS extension trial. Neurology. 2015;84:1582-91.

35. Johnson TA, Shames I, Keezer M, et al. Reconstitution of circulating lymphocyte counts in FTY720-treated MS patients. Clin Immunol. 2010;137:15-20.

36. Gonzalez-Cabrera PJ, Cahalan SM, Nguyen N, et al. S1P(1) receptor modulation with cyclical recovery from lymphopenia ameliorates mouse model of multiple sclerosis. Mol Pharmaco. 2012;81:166-74.

37. Piali L Froidevaux $S$, Hess $P$, et al. The selective sphingosine 1-phosphate receptor 1 agonist ponesimod protects against lymphocyte-mediated tissue inflammation. J Pharmacol Exp Ther. 2011;337:547-56.

38. Scott FL, Clemons B, Brooks J, et al. Ozanimod (RPC1063) is a potent sphingosine-1-phosphate receptor-1 (S1P1) and receptor-5 (S1P5) agonist with autoimmune disease-modifying activity. Br J Pharmacol. 2016;173:1778-92

39. Brossard P, Derendorf $\mathrm{H}, \mathrm{Xu}$ J, et al. Pharmacokinetics and pharmacodynamics of ponesimod, a selective S1P1 receptor modulator, in the first-in-human study. Br I Clin Pharmacol. 2013;76:888-96

40. Olsson T, Boster A, Fernandez O, et al. Oral ponesimod in relapsing-remitting multiple sclerosis: a randomised phase II trial. J Neurol Neurosurg Psychiatry. 2014;85:1198-208.

41. Jurcevic $\mathrm{S}$, Juif $P E$, Hamid $\mathrm{C}$, et al. Effects of multiple-dose ponesimod, a selective S1P1 receptor modulator, on lymphocyte subsets in healthy humans. Drug Des Devel Ther. 2017;11:123-31.

42. Tran JQ Hartung JP, Peach RJ, et al. Results from the first-in-human study with ozanimod, a novel, selective sphingosine-1-phosphate receptor modulator. I Clin Pharmacol. 2017; $57: 988-96$

43. Cohen JA, Arnold DL, Comi G, et al. Safety and efficacy of the selective sphingosine 1-phosphate receptor modulato ozanimod in relapsing multiple sclerosis (RADIANCE): a randomised, placebo-controlled, phase 2 trial. Lancet Neurol. 2016;15:373-81

44. Cohen JA, Comi G, Selmaj K, et al. Ozanimod vs interferon $\beta$-1a: clinical and MRI results of RADIANCE part B - a 2-year phase 3 trial in relapsing multiple sclerosis. Presented at MS Paris 2017 7th Joint ECTRIMS-ACTRIMS Meeting, 25-8 October 2017, Paris, France. Abstr. \#A-858-0000-02736.

45. Comi G, Kappos L, Selmaj KW, et al. Ozanimod demonstrates efficacy and safety in a phase 3 trial of relapsing multiple efficacy and safety in a phase 3 trial of relapsing multiple
sclerosis (SUNBEAM). Presented at MS Paris2017, 7th Joint ECTRIMS-ACTRIMS Meeting 25-8 October 2017, Paris, France ECTRIMS-ACTRIMS Meeting,

46. Kappos L, Arnold DL, Bar-Or A, et al. Safety and efficacy of amiselimod in relapsing multiple sclerosis (MOMENTUM): randomised, double-blind, placebo-controlled phase 2 tria. Lancet Neurol. 2016;15:1148-59.

47. Sugahara K, Maeda Y, Shimano K, et al. Amiselimod, a novel sphingosine 1-phosphate receptor-1 modulator, has potent therapeutic efficacy for autoimmune diseases, with low bradycardia risk. Br J Pharmacol. 2017;174:15-27.

48. Gergely P, Nuesslein-Hildesheim B, Guerini D, et al. The selective sphingosine 1-phosphate receptor modulator BAF312 redirects lymphocyte distribution and has species-specific effects on heart rate. Br J Pharmacol. 2012:167:1035-47.

49. Kappos L, Bar-Or A, Cree B, et al. Efficacy of siponimod in secondary progressive multiple sclerosis: results of the phase 3 study (CT.002). Neurology. 2017;88(16 Supplement).

50. Grogan K, Merck KGaA gives up on MS drug ceralifimod, 2014 Available at: www.pharmatimes.com/news/merck_kgaa_gives up_on_ms_drug_ceralifimod_1002072 (accessed 9 October 2017)

51. Nishi T, Miyazaki S, Takemoto T, et al. Discovery of CS-0777: a potent, selective, and orally active S1P1 agonist. ACS Med Chem Lett. 2011;2:368-72.

52. Xu J, Gray F, Henderson A, et al. Safety, pharmacokinetics, pharmacodynamics, and bioavailability of GSK2018682, a sphingosine-1-phosphate receptor modulator in healthy volunters. Clin Pharmacol Drug Dev. 2014:3:170-8.

3. Park SI, Im DS, Sphingosine 1-phosphate receptor modulators and drug discovery. Biomol Ther (Seoul). 2017;25:80-90.

54. Jeffery DR, Rammohan KW, Hawker K, Fox E. Fingolimod: a review of its mode of action in the context of its efficacy and safety profile in relapsing forms of multiple sclerosis. Expert Rev Neurother. 2016;16:31-44.

55. Subei AM, Cohen JA. Sphingosine 1-phosphate receptor modulators in multiple sclerosis. CNS Drugs. 2015;29:565-75 